\title{
The Economics of Integrated Depression Care: The University of Michigan Study
}

\author{
Kyle L. Grazier ${ }^{1,3}$ and Michael S. Klinkman²
}

\begin{abstract}
A goal of the Robert Wood Johnson Depression and Primary Care Initiative at the University of Michigan is to create and implement the clinical care and financial systems necessary to enable links between primary care and mental health specialty depression care. This paper describes the economic issues related to resources required, the mechanisms to distribute those resources, and the support that must be garnered from stakeholders. By systematic measurement and application, we assess the cost, price and selected consequences of these efforts. The study illustrates the need for both centralized and distributed capacity and support for innovative models of care.
\end{abstract}

KEY WORDS: costs; depression; economics; primary care.

Implementing evidence-based depression care through primary care service delivery systems presents unique challenges to patients, providers, and payers. Most people who seek care for depression do so through the primary care system, rather than through a mental health specialty system (Katon et al., 2002). Several studies have found positive associations between screening, early intervention and good clinical outcomes (Edlund, Unutzer, \& Wells, 2004; Katon et al. 2004; Kilbourne, Rollman, Schulberg, Herbeck-Belnap, \& Pincus, 2002; Oxman, Dietrich, \& Schulberg, 2003; Pignone et al., 2002; Simon, 2002; Weingarten et al., 2002). However, a recent generation of studies evaluating enhanced screening and case management have also shown among certain populations that improvements are not sustained over time (Aubert et al., 2003; Katzelnick et al., 2000; Katon, Unutzer, \& Simon,

\footnotetext{
${ }^{1}$ Department of Health Management and Policy

${ }^{2}$ Department of Family Medicine, both at the University of Michigan.

${ }^{3}$ Correspondence should be directed to Kyle L. Grazier, Department of Health Management and Policy, University of Michigan, 109 S. Observatory Street, Ann Arbor, MI 48109; Phone: 734.936.1222; e-mail: kgrazier@umich.edu.
}

2004b; Simon et al., 2001; Unutzer et al., 2002). To an already overburdened primary care practice, and particularly one at financial risk for services delivered, the desire to provide quality depression care can be compromised by the stark reality of the prevalence of the disease, inadequate procedurebased payment systems, unrelated information systems, isolated clinical expertise, and inefficient communication channels (Katon, Lin, Russo, \& Unutzer, 2000; Kessler et al., 1994, 2003; Kilbourne et al., 2004; Simon, 2002). Solutions for an integrated delivery system or for a stand-alone specialty practice may not be effective or efficient in a public academic medical center. Highlighted in this paper are the economic issues related to understanding the resources required, the mechanisms to distribute those resources, and the support that must be derived from associated stakeholders. The study illustrates the need for both centralized and distributed capacity and support for innovative models of care.

The primary goal of the University of Michigan demonstration site of the Robert Wood Johnson Foundation Depression and Primary care initiative is to create and implement the clinical care and financial systems necessary to enable links between 
primary care and mental health specialty depression care. By systematic measurement and application of a resource-based economic model, we assess the cost, price and selected consequences of these efforts.

\section{THE SETTING FOR THE DEMONSTRATION}

The University of Michigan Health System (UMHS), in which the demonstration is taking place, is composed of several hospitals; outpatient primary and specialty care clinics, and comprehensive and specialty centers all within an approximately 30 -mile radius. The UMHS also created and currently administers a regional Health Maintenance Organization, M-Care, which serves as the main third party involved in the demonstration. A faculty practice plan provides the administrative structure to support the clinical care offered by clinical faculty.

To meet our primary goal, we needed to align clinical processes and economic incentives to enable coordinated "best practice" treatment of depression across primary care, specialty care, and disability management settings. We created a set of clinical processes tailored to meet the needs of primary care practices for use across all health plans that: (1) provide care management services matched to level of depression severity; (2) provide ongoing disease monitoring and clinician feedback at the individual patient level; (3) provide the information infrastructure to facilitate disease monitoring and clinical communication; and (4) provide patient education and self-management skills. We also developed an economic model that enabled us to understand, then modify and model the impact of alternative financial incentives to sustain this integrated care model.

Stakeholders include those effecting and impacted by changes in organization and financing of services: the faculty practice plan, the employer purchasers of services, medical center and clinic administration, the physician and nurse providers, and patients. The key partners are the UMHS and Ford Motor Company, and two health plans closely linked to each of the partners, Partnership Health and M-Care. Partnership Health is a unique FFS plan jointly created by Ford Motor Company and the UMHS, with roughly 2,300 enrollees. M-Care, as noted above, is a UMHS-owned managed care organization covering over 140,000 lives in southeastern Michigan, with approximately 80,000 members in its HMO and POS product lines $(65,000$ commercial, 9,000 Medicaid, 5,000 Medicare) receiving both primary and specialty care within the University of Michigan Faculty Group Practice (FGP). All patients included in this demonstration reside in southeast Michigan and receive primary health care from physicians in the FGP.

The core mission of this partnership is to provide integrated, patient-centered depression care for its defined populations in a sustainable program. To carry out this mission, UMHS clinicians and researchers have created the Michigan Depression Outreach and Collaborative Care (M-DOCC) program, which applies evidence-based disease management, collaborative case management, and information management methods to the care of depression across primary and specialty care settings at UMHS. M-DOCC provides the core elements of the clinical care model employed in this project.

The FGP, the provider group in which the intervention takes place, is the UMHS physician contracting organization. It includes all 1,200 UMHS physician faculty. Primary care faculty include family physicians (47), general internists (50), internal medicine/pediatricians (8) obstetrician-gynecologists (31), and general pediatricians (32) in 14 clinical sites. The financial structure supporting the departments differs. For primary care, the FGP contracts with several health plans that offer payment mechanisms ranging from full fee for service to full capitation. The FGP, rather than individual department, receives the revenues, from which a negotiated portion of their billed charges and/or capitation payment(s) are distributed to the department. In addition, the departments pay primary care physicians a combination of academic salary and clinical incentive pay. The relative proportion of salary to incentive pay varies by department and is adjusted regularly, but in each department the clinical incentive is based on relative value units generated during clinical care. There are at least as many PCP salary arrangements as there are clinical departments.

The Michigan Center for Diagnosis and Referral (M-CDR), the managed behavioral health organization (MBHO) created by the UMHS Department of Psychiatry, is composed of $\mathrm{U}-\mathrm{M}$ and community-based mental health professionals and holds the capitated behavioral health contract with M-Care. Almost all M-Care members receiving specialty mental health care services will be seen by M-CDR clinicians. As the Department of Psychiatry is also included in the FGP, a negotiated amount of FGP funds are released to the Department to cover its capitated mental health clinical activity. 
Typical challenges to integrated care exist even within a world-class medical center. Clinical departments occupy separate spaces, cost accounting systems can be unique to the departments, providers are in demand, and responsibilities of the clinical faculty require juggling clinical care, teaching, and research to maintain faculty appointments. Economic incentives to practice integrated care can be thwarted by a billing system only recently integrated across departments, multiple payers with multiple administrative requirements, and clinical nurse shortages. However, there are clear advantages to attempting such a model in this particular system. The medical school, faculty group practice, and managed care plan are under the same health system leadership and operate under a shared research, teaching and community service mission, encouraging innovation and making integrated strategic planning more efficient. Geographically, the units are in close proximity, located within or near to a moderately sized city. A few large employers dominate membership in health plans, making standardization of benefit plans more likely. The success in the application of the chronic care clinical model to depression has accelerated needed recognition of the supporting information structures, patient flow models and the financing and payment schemes required to test and sustain needed changes.

\section{THE FINANCIAL MODEL}

To address and respond to critical economic aspects of integration, we focus on three areas: pricing service integration, paying the costs of integration, and financing depression management. All three areas require investigators to understand: the cost structure of components of the integrated services; the payment models currently in place; the components necessary to sell the "product" to the private and public sectors.

\section{Pricing Service Integration}

Pricing relies on knowledge of the direct and indirect cost components of the disease management process and its integration into usual care. Costing involved use of traditional cost accounting and industrial engineering methods to compute cost of care management. The study collected detailed task (categories and free form) and time (in minutes) from all nurse navigators for 4 months. These data were then used to compute and allocate the direct labor costs to nurse, patient, and task. Site and departmental administrative records supplied indirect costs estimates of labor and materials. Outcome data, including PHQ scores, hospitalizations, and emergency department visits are collected to correlate outcomes with service use and costs.

Wages and benefits for the nurse navigators for time spent in contacting the client, discussing health status, and managing care dominate the cost structure for nurse care management. Telephone and office space rental fees contribute a small portion to total costs. Some redundancy of cost collection is built into the system through shadow billing for the nurse manager time using a combination of standard CPT codes and newly created project codes. This results in some overestimation of costs for data collection. Data on diagnoses, severity levels, and PHQ scores are accessible by encounter and integrated into the model to estimate the relationship between levels of severity as measured and resources consumed. More difficult to assess is the potential effect of the data system on the quality of the interaction or the efficiency of the contact.

\section{Paying the Costs of Integration}

Once the resources consumed in delivering care management services within the M-DOCC program are assigned monetary values, billable service units consistent with the payment system in place in the sites are created. These are assigned a code recognizable to the accounting system and to the users of the medical bill. Current provider fees are based on relative value units assigned to conventional CPT codes multiplied by a cost factor. Consistent with the format and presentation of these codes, new codes ("X-codes") were created that reflect levels of resource consumption for care management by nurse navigators as well as comparable services provided by physicians. The cost factors for physicians or for the nurse navigators are then applied to the resource units (time increments potentially weighted by severity.)

Physicians in the selected clinical sites are currently paid a salary by the Faculty Group Practice plan and a bonus based on an individual provider's incremental service units over a predetermined level. Primary care physicians in the Plan are not held at risk for pharmacy costs, inpatient services, 
or ancillary service costs. The inclusion of service units for depression treatment allows physicians to be compensated for the additional time spent treating patients. The addition of nurse navigator service/billing units permits compensation by payers for these services. Quantifying the treatment services and the patient outcomes in monetary units provides data of use to physician practices, employers and, other purchasers.

\section{Financing Depression Management}

A major objective of the demonstration is to provide data to support the financial and clinical viability of this integrated program. We sought stakeholder feedback on critical indicators used by purchasers to establish returns on investment. Current payers and employers are open to covering increased fees resulting from this new model if the fees are "reasonable" and if the services they buy result in improved health status, decreased disability and work absences, effective care and efficient use of resources.

Patient sociodemographic characteristics, diagnoses, functional status, provider type, and services (outpatient, inpatient, mental health, medical and pharmacy), and their standardized fees and paid costs are derived from registry sources, claims (encounter) files, pharmacy reports, and surveys. The data provide a basis for calculating the total resources used to provide care and a model of the direction and strength of their relationships.

Assessing the full cost of the case management services, including the direct costs and any offsets that might result from the use of the services is the first step in determining the economic viability of the model. In the long term, however, other cost implications need estimation. These include increases in demand for the service due to new case finding, more severely ill cases, or a biased selection of providers or care sites.

The economic implications of unintended incentives arising from the application of the integrated model also warrant examination. If physician profiling methodologies were in use, would they risk adjust for the added complexity and therefore the added costs and time for integrated care? In measuring efficiency of services, would the models incorporate the added inputs required for chronic depression care? What effects will changes in tier structure for pharmacy benefits among health plan enrollees and increased prescription costs have on adherence to pharmacotherapy and on any future physician "withhold" fund formula for pharmacy? We collect data on pharmacy use by patients, pharmacy costs to the practices, and the consequent size of the pharmacy fund. Other environmental changes related to the practice of medicine in the sites or changes in system management require monitoring over the course of the demonstration.

\section{CHALLENGES}

The challenges of integrating depression care and primary care within an academic medical center are conceptual and operational. Conceptually, academic centers are uniquely poised to explore and adopt clinical innovations; however, they are also constrained financially, as are most service institutions. This potential conflict requires demonstration that that an economic-clinical balance can be achieved. This in turn requires testimony that purchasers can and will compensate the service units for the higher quality care. Thus, efforts to measure short and long-term outcomes of the new technology or services must answer critical questions of sustainability.

Operationally, many tasks are data related. Identifying patients in need in the population, at the point of service, and for follow up requires real time and archival information system capabilities, as well as electronic medical records with ties to cost accounting and billing systems. Provider payment systems and profiling methods must be capable of reflecting the patient severity and complexity and must recognize the need for treatment integration not only at time of visit but beyond.

The close geographic proximity of the practice sites, academic departments, and hospitals, and the university affiliation of all the clinicians were an advantage at the University of Michigan's demonstration. Promotion of the project was enabled by site visits, co-location of practitioners, and faceto-face contacts with administrators and other decision makers.

Despite the unique challenges faced by each of the demonstration sites, there are clearly generic and generalizable principles underlying the evidence that depression care and primary care are more effective if integrated. The lessons learned 
from each of the Robert Wood Johnson Foundation sponsored efforts will result in the more rapid dissemination of the necessary clinical and economic components of these evidence-based best practices.

\section{ACKNOWLEDGMENT}

This work was supported in part by the Robert Wood Johnson Foundation Grant \#048171.

\section{REFERENCES}

Aubert, R. E., Fulop, G., Xia, F., Thiel, M., Maldonato, D., \& Woo, C. (2003). Evaluation of a depression health management program to improve outcomes in first or recurrent episode depression. American Journal of Managed Care, 9, 374-380.

Edlund, M. J., Unutzer, J., \& Wells, K. B. (2004). Clinician screening and treatment of alcohol, drug, and mental problems in primary care: results from healthcare for communities. Medical Care, 42(12), 1158-1166.

Katon, W., Lin, E., Russo, J., \& Unutzer, J. (2003). Increased medical costs of a population-based sample of depressed elderly patients. Archives of General Psychiatry, 60(9), 897903.

Katon, W., Russo, J., Von Korff, M., Lin, E., Simon, G., Bush, T., Ludman, E., \& Walker, E. (2002). Long-term effects of a collaborative care intervention in persistently depressed primary care patients. Journal of General Internal Medicine, 17(10), 741-748.

Katon, W. J., Simon, G., Russo, J., Von Korff, M., Lin, E. H. B., Ludman, E., Ciechanowski, P., \& Bush, T. (2004a). Quality of depression care in a population-based sample of patients with diabetes and major depression. Medical Care, 42(12), 12221229.

Katon, W. J., Unutzer, J., \& Simon, G. (2004b). Treatment of depression in primary care: where we are, where we can go. Medical Care, 42(12), 1153-1157.

Katzelnick, D. J., Simon, G. E., Pearson, S. D., Manning, W. G., Helstad, C. P., Henk, H. J., Cole, S. M., Lin, E. H., Taylor, L. H., \& Kobak, K. A. (2000). Randomized trial of a depression management program in high utilizers of medical care. Archives of Family Medicine, 9, 345-351.
Kessler, R. C., Berglund, P., Demler, O., Jin, R., Koretz, D., Merikangas, K. R., Rush, A. J., Walters, E. E., \& Wang, P. S. (2003). National Comorbidity Survey Replication. The epidemiology of major depressive disorder: Results from the National Comorbidity Survey Replication (NCS-R). Journal of the American Medical Association, 289(23), 3095-3105.

Kessler, R. C., McGonagle, K. A., Zhao, S., Nelson, C. B., Hughes, M., Eshleman, S., Wittchen, H., \& Kendler, K. S. (1994). Lifetime and 12-month prevalence of DSM-III-R psychiatric disorders in the United States: results from the National Comorbidity Survey. Archives of General Psychiatry, 51, 8-19.

Kilbourne, A. M., Rollman, B. L., Schulberg, H. C., HerbeckBelnap, B., \& Pincus, H. A. (2002). Clinical Framework for Depression Treatment in Primary Care. Psychiatric Annals, 32(9), 545-555.

Kilbourne, A. M., Schulberg, H. C., Post, E. P., Rollman, B., Herbeck-Belnap, B., \& Pincus, H. A. (2004). Translating evidence-based depression management services to community-based primary care practices. Milbank Quarterly, 82(4), $631-659$.

Lowe, B., Unutzer, J., Callahan, C., Perkins, A. J., \& Kroenke, K. (2004). Monitoring depression treatment outcomes with the patient health questionnaire-9. Medical Care, 42(12), 11941201.

Oxman, T. E., Dietrich, A. J., \& Schulberg, H. C. (2003). The depression care manager and mental health specialist as collaborators within primary care. American Journal of Geriatric Psychiatry, 11, 507-516.

Pignone, M., Gaynes, B. N., Rushton, J. L., Burchell, C. M., Orleans, C. T., Mulrow, C. D., \& Lohr, K. N. (2002). Screening for depression in adults. Annals of Internal Medicine, 136(10), $765-776$.

Simon, G. (2002). Implementing depression treatment guidelines. Current Opinion in Psychiatry, 15, 77-82.

Simon, G. E., Manning, W. G., Katzelnick, D. J., Pearson, S. D., Henk, H. J., \& Helstad, C. P. (2001). Cost-effectiveness of systematic depression treatment for high utilizers of general medical care. Archives of General Psychiatry, 58(2), 181-187.

Unutzer, J., Katon, W., Callahan, C. M., Williams, J. W., Jr. Hunkeler, E., Harpole, L., Hoffing, M., Della Penna, R. D., Noel, P. H., Lin, E. H., Arean, P. A., Hegel, M. T., Tang, L., Belin, T. R., Oishi, S., \& Langston, C. (2002). Collaborative care management of late-life depression in the primary care setting: a randomized controlled trial. Journal of the American Medical Association, 288(22), 2836-2845.

Weingarten, S. R., Henning, J. M., Badamgarav, E., Knight, K., Hasselblad, V., Gano, A., \& Ofman, J. J. Jr. (2002). used in disease management programmes for patients with chronic illness-which ones work? Meta-analysis of published reports. British Medical Journal, 325(7370), 925. 